\title{
Cytotoxicity and Changes in Gene Expression Under Aluminium Potassium Sulfate on Spodoptera Frugiperda 9 Cells
}

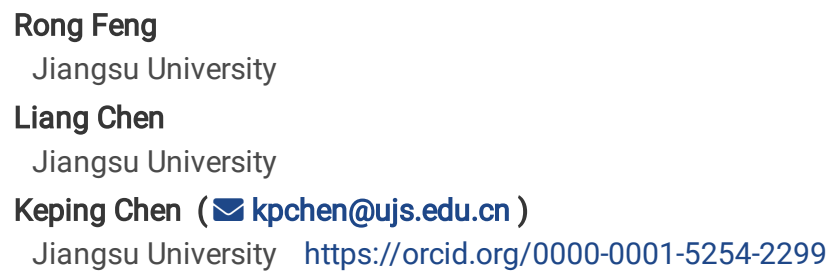

\section{Research Article}

Keywords: aluminium, mTOR pathway, glutathione metabolism, SF9 cells, apoptosis

Posted Date: March 22nd, 2021

DOl: https://doi.org/10.21203/rs.3.rs-316200/v1

License: (a) This work is licensed under a Creative Commons Attribution 4.0 International License. Read Full License

Version of Record: A version of this preprint was published at Ecotoxicology on September 21st, 2021. See the published version at https://doi.org/10.1007/s10646-021-02478-3. 


\section{Abstract}

Aluminium, a substance found in large amounts in nature, has been widely used for various purposes, especially food additives. The effects of long-term and excessive exposure to aluminium on human health are receiving increasing attention. The extensive human use of aluminium food additives can also cause aluminium to enter the ecosystem, where it has significant impacts on insects. This study explored the cytotoxicity and changes in gene expression under aluminium potassium sulfate toward Spodoptera frugiperda 9 cells. We found that high concentrations of aluminium resulted in cell enlargement and cell membrane breakage, decreased cell vitality, and caused apoptosis. Through RNA-Seq transcriptomics, we found that aluminium ions may inhibit the expression of regulatory-associated protein of mTOR, tdlns-dependent protein kinase-1, and small heat shock proteins (heat shock $70 \mathrm{kDa}$ protein and crystallin alpha B), leading to changes in mTOR-related pathways (such as the longevity regulation pathway and PI3K-Akt signalling pathway), and promoting cell apoptosis. On the other hand, aluminium ions lead to the overexpression of GSH S-transferase邓prostaglandin-H2 D-isomerase and pyrimidodiazepine synthase, and induce intracellular oxidative damage, which ultimately affects cell growth and apoptosis through a series of cascade reactions.

\section{Introduction}

Aluminium, a ubiquitous element in nature, is widely used; it is present everywhere in the ambient environment. However, throughout biological evolution, aluminium has not been involved in the construction of the life, nor has it any beneficial physiological function in humans or in other organisms. Adverse skeletal, neurological, haematopoietic, and other effects associated with excessive aluminium exposure to human have been found in many studies (Bondy 2010; Hirata-Koizumi et al. 2011; Li et al. 2011; Sun et al. 2017).

Insects are the largest group of animals on Earth, accounting for approximately $60 \%$ of all animals (Wielkopolan and Obrępalska-Stęplowska 2016). They are so diverse that they can be found in almost every area of the world. Insects are important parts of the ecosystem but are highly affected by human beings. The extensive use of aluminium additives by humans can cause aluminium to enter the ecosystem, where it has significant impacts on insects. Increasing aluminium concentrations and exposure time have been found to shorten the lifespan of Drosophila and affect motor ability (Kijak et al. 2014). Aluminium also inhibits the growth of Bombyx mori and changes the expression of cAMP response element-binding protein and presenilin (Liu et al. 2018). For the aquatic insect Corixa punctata (Illig.), the toxicity of aluminium may be explained by its inhibitory action on $\mathrm{Na}^{+}$influx (Witters et al. 1984). Therefore, continuous contact and accumulation of aluminium may have an impact on the growth and reproduction of insects, with possible effects at the ecosystem level.

The toxicity of aluminium has been a concern for many years, but no conclusions have been reached about its toxic mechanisms. Moreover, most studies have mainly focused on mammals and mammalian cells; there have been few studies on the toxicity of aluminium on insects and almost no studies on the relevant mechanisms. In this study, Spodoptera frugiperda 9 (SF9) cells were used to study aluminium toxicity at the cellular and genomic levels. We investigated the alterations in cell growth and development caused by exposure to aluminium and verified some differentially expressed genes (DEGs). Our results suggest possible pathways for aluminium action and provide a theoretical reference for further exploration of the mechanism of action and methods to reduce aluminium accumulation.

\section{Materials And Methods}

\subsection{Cell culture and morphological observation}

SF9 cells were obtained from the Institute of Life Science, Jiangsu University, China, and were cultured in ESF 921 medium (containing 10\% streptomycin and penicillin) at $27^{\circ} \mathrm{C}$. Aluminium potassium sulfate dodecahydrate (APS) powder was purchased from Sinpharm Chemical Reagent Co., Ltd. (Shanghai, China). The APS powder was dissolved in ESF 921 medium, and the solution was then filtered through a $0.2 \mu \mathrm{m}$ membrane. The aluminium concentration in the filtered solution was detected by inductively coupled plasma optical emission spectrometry (ICP OES) (Santos et al. 2018; Zhou et al. 2010), and the result was $4.5 \mu \mathrm{g} / \mathrm{ml}$. This mother liquor was diluted with ESF 921 medium in a gradient of different aluminium concentrations for later use. About $5 \times 10^{5}$ cells were incubated in 6-well plates and placed for $12 \mathrm{~h}$ at $27^{\circ} \mathrm{C}$, and then entered the medium with different concentrations of aluminium $\left(2.25,4.5 \times 10^{-1}, 4.5 \times 10^{-2}, 4.5 \times 10^{-3}\right.$, and $\left.0 \mu \mathrm{g} / \mathrm{ml}\right)$. After incubation for $0,24,48$, and 72 $\mathrm{h}$, an inverted microscope (BX53: Olympus, Nanjing, China) was used to observe the morphological changes.

\subsection{Cell viability measurement}

A total of approximately $5 \times 10^{4}$ cells/well were moved into 96 -well plates and placed in a $27^{\circ} \mathrm{C}$ incubator for $12 \mathrm{~h}$. Then, the original medium was replaced with medium containing different concentrations of aluminium $\left(4.5,3.375,2.25,0.9,4.5 \times 10^{-1}, 2.25 \times 10^{-1}, 4.5 \times 10^{-2}, 4.5 \times 10^{-3}\right.$, and 0 $\mu \mathrm{g} / \mathrm{ml}$ ). Six replicates were set for each concentration group. After culturing for $72 \mathrm{~h}$, cell viability was evaluated by Cell Counting Kit-8 (CCK-8) assay (Bioworld Technology, Nanjing, China). The cells in each well were washed three times with phosphate-buffered saline (PBS), and then 100 $\mu \mathrm{l}$ of medium mixed with CCK-8 solution $(0.5 \mathrm{mg} / \mathrm{ml}, 10 \mu \mathrm{l})$ was added. After incubation at $27^{\circ} \mathrm{C}$ for $2 \mathrm{~h}$, the optical density at $450 \mathrm{~nm}\left(\mathrm{OD}_{450}\right)$ was measured by an enzyme-linked immunosorbent assay reader (Synergy H4: Bio-Tek, VT, USA). Cell viability was calculated by the following 
equation: viability $(\%)=\left(O D_{\text {treated }}-O D_{\text {blank }}\right) /\left(O D_{\text {untreated }}-O D_{\text {blank }}\right) \times 100 \%$. The viability of untreated cells was considered as $100 \%$. The halfmaximal inhibitory concentration $\left(\mathrm{IC}_{50}\right)$ was calculated by SPSS software.

\subsection{Apoptosis analysis}

\subsubsection{Morphological changes associated with apoptosis}

An acridine orange/ethidium bromide (AO/EB) strain kit (Solarbio, Beijing, China) was used to assess morphological changes in SF9 cells treated with different aluminium concentrations. Approximately $5 \times 10^{4}$ cells/well were plated in 6 -well plates $\left(1 \mathrm{ml} /\right.$ well) and incubated for $12 \mathrm{~h}$ at $27^{\circ} \mathrm{C}$, and then the original medium was replaced with aluminium-containing medium. After incubation for $72 \mathrm{~h}$, the medium in each well was removed, $1 \mathrm{ml}$ of PBS (containing $20 \mu \mathrm{l}$ of AO/EB staining solution) was added, and the cells were incubated in the dark for $2-3$ minutes at room temperature. The cells were then observed and photographs taken under an inverted fluorescence microscope (IX73: Olympus). Pick six different positions for each hole (from top to bottom on the two sides of the axis of symmetry of each hole, a total of 6 points, not near the edge of the hole) and count green, orange or red, respectively. Repeat three times.

\subsubsection{Apoptosis detection}

An Annexin-V-PE/7-AAD Apoptosis Detection Kit (BD Biosciences, San Diego, USA) was used to detect apoptosis. SF9 cells were treated with medium with different aluminium concentrations $\left(4.5 \times 10^{-1}, 4.5 \times 10^{-2}, 4.5 \times 10^{-3}\right.$ and $\left.0 \mu \mathrm{g} / \mathrm{ml}\right)$ for $72 \mathrm{~h}$ and washed with precooled PBS.

According to the manufacturer's protocol, Annexin-V, phycoerythrin (PE) and 7-AAD were added for staining. A FACSCalibur (BD Pharmingen, San Diego, USA) was used to acquire data, and FlowJo 7.6.4 software (TreeStar Inc., Ashland, USA) was used to analyse the data. Repeat three times. Then the proportion of cells in each stage of apoptosis was counted for statistical analysis.

\subsection{RNA extraction and Illumina sequencing}

Approximately $5 \times 10^{4}$ cells/well were planted in a medium containing 0 and $0.334 \mu \mathrm{g} / \mathrm{ml}\left(\mathrm{IC}_{50}\right)$ aluminium. Following culture for $72 \mathrm{~h}$, a total of $10^{6}$ SF9 cells were separated by centrifugation. Then the culture medium was removed and 1 ml of TRIzol (Invitrogen, Carlsbad, CA, USA) was added to lyse the cells. The cells were repeatedly aspirated until completely dissolved and submitted to Shanghai OE Biotech Co., Ltd. (Shanghai, China), for RNA extraction and sequencing. Total RNA was extracted using RNA Isolation Kit (Ambion) following the manufacturer's protocol. RNA integrity was evaluated using an Agilent 2100 Bioanalyzer (Agilent Technologies, Santa Clara, CA, USA). The samples with RNA integrity numbers (RINs) $\geq 7$ were subjected to subsequent analyses. Libraries were constructed using a TruSeq Stranded mRNA LTSample Prep Kit (IIlumina, San Diego, CA, USA) according to the manufacturer's instructions. Then, these libraries were sequenced on an Illumina sequencing platform (HiSeq ${ }^{\mathrm{T} M}$ 2500 or Illumina HiSeq X Ten), and 125 bp/150 bp paired-end reads were generated. The transcripts were obtained by using Trinity software with the paired-end method, and the longest transcript was selected as the unigene according to sequence similarity and length.

\subsection{Functional annotation}

The functions of the unigenes were annotated after alignment of the unigenes with sequences in the NCBI nonredundant (NR), Swiss-Prot, and euKaryotic Orthologous Group (KOG) databases using Blastx (Altschul 2012) with a threshold E-value of $10^{-5}$. The proteins with the greatest similarity to the unigenes were used to assign functional annotations. Based on the Swiss-Prot annotations, Gene Ontology (GO) classification was performed by mapping the relations between Swiss-Prot and GO terms. The unigenes were mapped to the Kyoto Encyclopedia of Genes and Genomes (KEGG) database (Kanehisa et al. 2008) for annotation of their potential metabolic pathways.

\subsection{Unigene quantification, DEG analysis, cluster analysis, and GO and KEGG enrichment}

The Fragments Per Kilobase of exon model per Million mapped fragments (FPKM) (Trapnell et al. 2010) and read count values of each unigene were calculated using bowtie2 (Langmead and Salzberg 2012) and eXpress (Roberts and Pachter 2013). DEGs were identified using the DESeq (2012) functions estimateSizeFactors and nbinomTest. A p value $<0.05$ and a fold change $>2$ were set as the thresholds for significant differential expression. Hierarchical cluster analysis of the DEGs was performed to explore transcript expression patterns. GO enrichment and KEGG pathway enrichment analyses of the DEGs were performed using R based on the hypergeometric distribution (http://www.r-project.org/). The result of the calculation returned a $p$ value of enrichment significance; a significant value indicated that the DEG showed enrichment for the $\mathrm{GO} /$ pathway entry. The $\mathrm{p}$ values and enrichment scores were calculated with the following equations:

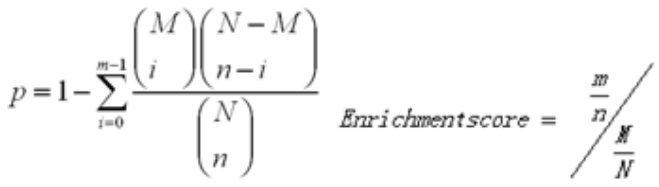


where $\mathrm{N}$ is the total number of unigenes with GO/KEGG annotations, $\mathrm{n}$ is the number of DEGs with the GO annotation in $\mathrm{N}$, $\mathrm{M}$ is the total number of unigenes annotated with a particular GO/KEGG term, and $\mathrm{m}$ is the number of DEGs in $\mathrm{M}$.

\subsection{Quantitative reverse real-time polymerase chain reaction (qRT-PCR) verification}

qRT-PCR was used to verify the transcriptome results. Following concentration detection, the extracted RNA (500 ng/ $\mu$ l) was reverse transcribed to synthesize cDNA using Q RT SuperMix for qPCR (Vazyme, Nanjing, China). The primers for qPCR are listed in Table 1, and 28S ribosomal RNA was used as a reference gene. qRT-PCR was performed using a 7300 Fast system (ABI, CA, USA) and SYBR Green Master Mix (Vazyme, Nanjing, China). The experiment was repeated three times, and all primers were designed from the nucleotide database of NCBI (www.ncbi.nlm.nih.gov/nuccore/). The relative gene expression levels were calculated using the $2^{-\Delta \Delta C t}$ method. All samples were measured in triplicate independently, and the results are presented as the mean \pm standard deviation (SD).

Table 1

The primer sequence and length of the target gene.

\begin{tabular}{|lllll|}
\hline Gene & Primers forward $\left(\mathbf{5}^{\prime} \mathbf{-} \mathbf{3}^{\prime}\right)$ & Length $\mathbf{( b p )}$ & Primers reverse $\left(\mathbf{3}^{\prime} \mathbf{- 5} \mathbf{5}^{\prime}\right)$ & Length $(\mathbf{b p )}$ \\
\hline HSPA1 & ATGGCCAAGATGCATGGGG & 19 & TCCGCTGTTGTGGTTTCCTC & 20 \\
\hline CRYAB & TCTCAGTGTTCGGGAGGGAT & 20 & TGGTCCGGGGTGAAATTCTG & 20 \\
\hline PDPK1 & AGTGAGGTCCGTGCTCCTAT & 20 & CTCGGTACCGGAGATGAAGC & 20 \\
\hline RAPTOR & CCGAGTGTCCTTGTGTCGAA & 20 & GGTGGTCCCTCCTAGTTTGC & 20 \\
\hline GST & AGAGGCTTTGGACCTCAAGGA & 21 & GGTACAAATCATCAGTTTTGCCG & 23 \\
\hline HPGDS & CCGTTTGCTGCTGGCTTATG & 20 & TTGCCAAGGTAACGGCAGAT & 20 \\
\hline SE & GAAGAAGGCCGTGGACAAGA & 20 & TCCATCGAGGAACTTGGTGC & 20 \\
\hline 28S & CTCAGAACTGGCACGGACA & 19 & TTAGATGACGAGGCATTTGG & 20 \\
\hline
\end{tabular}

\section{Results}

\subsection{Effect of APS on cell morphology}

When SF9 cells were treated with APS at different concentrations, the cell morphology changed with increasing APS concentrations (Fig. 1). The cells in the control group were uniformly round, with good refractive index values and tightly adherent walls. With increasing concentration and time, the cells in the APS treatment group gradually became larger, with blurry edges and broken cells, and the contents streamed out. These findings indicated that APS was toxic to SF9 cells in a time- and concentration-dependent manner, leading to morphological changes.

\subsection{Effect of APS on cell viability}

The concentration-response curve constructed from the $\mathrm{OD}_{450}$ results measured by an enzyme-linked immunosorbent assay reader demonstrated that cell viability decreased in response to increasing APS exposure (Fig. 2). Results were expressed as mean \pm SD, compared by one-way ANOVA followed by Bonferroni (pष0.05). The $\mathrm{IC}_{50}$ value was calculated as $0.334 \pm 0.035 \mu \mathrm{g} / \mathrm{ml}$ (mean $\pm \mathrm{SE}$ ).

\subsection{Morphological analysis of apoptosis}

AO can cross the cell membranes of normal living cells and dye DNA green, while EB can cross damaged cell membranes and stain DNA orange or red. Microscopy revealed that the number of cells stained green decreased gradually with increasing APS concentrations, while the number of cells stained orange and red increased gradually, indicating a trend of cell damage and apoptosis (Fig. 3, Table S1). And the cells proliferation was also inhibited.

\subsection{Flow cytometric analysis of apoptosis}

Annexin V/PE staining at different stages of apoptosis and flow cytometry analysis were performed to determine the apoptotic effect of aluminium exposure on SF9 cells. Compared with the control group, the groups exposed to increasing APS concentrations exhibited significant decreases in the percentages of cells gated in quadrant Q4 (normal cells) but gradual increases in the percentages of cells in quadrants Q3 (early apoptotic cells), Q2 (late apoptotic cells) and Q1 (dead cells) (Fig. 4, Table S2), suggesting that aluminium induced apoptosis in a dosedependent manner.

\subsection{Illumina sequencing, de novo assembly, and unigene quantification}

The mRNA sequences enriched from SF9 cells were analysed by the Illumina platform, and the raw reads of the treatment group and control group were obtained (Table 2). The transcripts were obtained by using Trinity software with the paired-end method, and the longest transcript was 
selected as the unigene according to sequence similarity and length. Then, cd-hit software was used to cluster the reads to remove redundancy. The final unigene set included 20,644 sequences with an average length of $1418.06 \mathrm{bp}$ (Table 3). The expression level of each unigene was directly reflected by its abundance (a higher gene abundance yielded a higher gene expression level). The expression levels of the unigenes calculated by the FPKM method are shown in Table 4. Overall, the average read counts were high, indicating that the measured values and theoretical values were very consistent and that the sequencing results were reliable.

Table 2

List of results of sequencing data quality pretreatment.

\begin{tabular}{|c|c|c|c|c|c|c|c|}
\hline Sample & Raw reads & Raw bases & Clean reads & Clean bases & Valid bases & Q30 & GC \\
\hline Control_1 & 49411448 & 7411717200 & 48033170 & 7040912750 & $95.00 \%$ & $95.10 \%$ & $46.76 \%$ \\
\hline Control_2 & 49531390 & 7429708500 & 48258488 & 7081135342 & $95.31 \%$ & $95.28 \%$ & $46.24 \%$ \\
\hline Control_3 & 49488662 & 7423299300 & 48149260 & 7047245323 & $94.93 \%$ & $95.23 \%$ & $46.18 \%$ \\
\hline Treat_1 & 45445902 & 6816885300 & 44000894 & 6450301838 & $94.62 \%$ & $94.95 \%$ & $46.21 \%$ \\
\hline Treat_2 & 49710304 & 7456545600 & 48393774 & 7094815137 & $95.15 \%$ & $95.26 \%$ & $46.25 \%$ \\
\hline Treat_3 & 49746894 & 7462034100 & 48189060 & 7058130742 & $94.59 \%$ & $94.85 \%$ & $46.13 \%$ \\
\hline
\end{tabular}

Raw reads: number of original reads; Raw bases: the original sequencing quantity or the number of bases; Clean reads: number of clean reads obtained after filtration; Clean bases: the amount of sequencing obtained after filtration, namely the number of bases; Valid base: Effective base percentage; Q30: percentage of bases with a Phred value of more than 30 in raw bases;GC: or as a percentage of the total number of bases of $\mathrm{G}$ and $\mathrm{C}$ in bases bases,

Table 3

Splicing result statistics

\begin{tabular}{|lllllllll}
\hline Term & All(>300bp) & >=500bp & >=1000bp & N50 & Total Length & Max Length & Min Length & Average Length \\
\hline Unigene & 20644 & 14485 & 9050 & 2361 & 29274446 & 30443 & 301 & 1418.06
\end{tabular}

All(> 300bp): Length > 300 bp number of Unigene; >=500bp: Length > 500 bp number of Unigene; >=1000bp: Length >= 1000 bp number of Unigene; N50: The sequence length when the length value of the scanned sequence exceeds $50 \%$ of the total sequence length for the first time. Total Length: Total base number of Unigene; Max Length: Longest Unigene length; Min Length: Shortest Unigene length.

Table 4

Distribution statistics of FPKM value of Unigene.

\begin{tabular}{|llllllllll}
\hline Sample & Min & 1st_Qu & Median & Mean & 3rd_Qu & Max & Sd & Sum & \\
\hline Control_1 & 0 & 1.963051 & 7.2748045 & 42.3266274590436 & 25.26907 & 30409.24 & 303.306817282368 & 873790.897264495 \\
\hline Control_2 & 0 & 1.8822495 & 7.062499 & 42.9933487909485 & 25.425765 & 35096.1 & 332.412572870023 & 887554.69244034 \\
\hline Control_3 & 0 & 1.58741 & 6.7128495 & 45.2333367301889 & 25.425255 & 38341.5 & 363.787326294455 & 933797.00345802 \\
\hline Treat_1 & 0 & 2.805947 & 7.9212745 & 43.1512357689392 & 26.316915 & 30396.47 & 306.152590696151 & 890814.11121398 \\
\hline Treat_2 & 0 & 2.8982615 & 7.893373 & 43.1670165276212 & 26.47116 & 31521.5 & 317.273197078836 & 891139.889196212 \\
\hline Treat_3 & 0 & 2.4279275 & 7.4123635 & 46.4869436866397 & 26.188035 & 37938.19 & 375.11233985974 & 959676.46546699 \\
\hline
\end{tabular}

Min: minimum; 1st Qu: first quartile; Median: median; Mean: average; 3rd Qu: third quartile; Max, maximum; Sd: standard deviation; Sum: summation.

\subsection{Differential gene expression changes and functional annotation}

A total of 1423 DEGs were obtained, of which 1248 were upregulated and 175 were downregulated (Fig. 5). Unigenes in the same cluster may have similar biological functions. Unsupervised hierarchical clustering analysis was performed on the expression levels of different unigenes, as shown in Fig. 6. Red indicates high expression of unigenes, while blue indicates low expression of unigenes.

After obtaining the DEGs, we conducted GO enrichment analyses on the DEGs and described their functions (combined with GO annotation results). The top 30 terms were selected (GO entries with unigene differences greater than 2 in the three categories were screened and sorted by the $-\log 10 \mathrm{p}$ value corresponding to each entry from largest to smallest) (Fig. 7). The standard GO classification covers three aspects of biology: 
biological processes, cellular components, and molecular function. The classification helped elucidate how these DEGs affect biological function after aluminium treatment.

To identify the effects of aluminium on the activation of biological pathways and the apoptosis mechanism of SF9 cells, we conducted pathway analysis on the DEGs using the KEGG database (combined with KEGG annotation results), and the top 20 pathways were selected (Fig. 8). The following pathways had the greatest numbers of DEGs: drug metabolism-cytochrome P450 (CYP), metabolism of xenobiotics by CYP, the longevity regulation pathway, glutathione metabolism, pentose and glucuronate interconversion, and others. Through further level 2 analysis, we found that the DEGs were mainly associated with cellular processes, environmental information processing, metabolism, genetic information processing, organismal systems, and other pathways (Fig. 9). Among these DEGs, the upregulated genes were mainly associated with metabolic pathways, while the downregulated genes were mostly associated with other pathways (Fig. 10).

\section{7 qRT-PCR verification}

To validate the accuracy of the Illumina sequencing data, 7 DEGs were selected for qRT-PCR analysis. The results showed that the DEG expression profiles exhibited trends similar to those obtained with the RNA-Seq samples (Fig. 11), indicating the reliability of the transcriptional abundance data for these DEGs.

\section{Discussion}

Most studies on the toxicity of aluminium, whether they have involved animal or cell experiments, have used $\mathrm{AlCl}{ }_{3}, \mathrm{Al}_{2}\left(\mathrm{SO}_{4}\right)_{3}$, and $\mathrm{Al}\left(\mathrm{NO}_{3}\right)_{3}(\mathrm{Foglio}$ et al. 2012; Shrivastava 2012; Sood et al. 2012; Sun et al. 2009; Zhuang et al. 2016). APS has rarely been used. In China, only APS is allowed to be added to food as a leavening agent (Zhang et al. 2016). Therefore, to explore the mechanism of aluminium toxicity, APS was selected as the experimental reagent in this study.

The present study demonstrated that APS changed SF9 cell morphology, lowered cell viability, induced apoptosis, and altered gene expression. Treating SF9 cells with increasing APS concentrations caused the cells to become increasingly enlarged and clustered. As the incubation time increased, the cell membranes became more blurred, and the cellular contents flowed out. The IC50 of SF9 cells treated with APS for 72 hours was $0.334 \mu \mathrm{g} / \mathrm{ml}$ (equivalent to $12.4 \mu \mathrm{M}$ ), which was similar to human lymphocytes 10-20 $\mu \mathrm{M}$ (Aluminium chloride) (Paz et al. 2017). While the Chen et al. treated SH-SY5Y cells with Al maltolate for $24 \mathrm{~h}$, and the cell bodies, neuritis and viability decreased when the concentration of aluminium exceeds $400 \mu \mathrm{M}$ (Chen et al. 2011). After treating Rat gliatoma $\mathrm{C} 6$ cells with $\mathrm{AlCl} 3 \cdot \mathrm{H} 2 \mathrm{O}(1-8 \mathrm{mM})$ for $24 \mathrm{~h}$, the rate of apoptotic and necrotic cells increased(Zhang et al. 2010). One of the reasons for the difference in these in vitro results is due to the different chemical properties of different Al-containing compounds. The bioavailability and solubility of aluminium are affected by its hydrolytic morphology(Crisponi et al. 2012). The main species at $\mathrm{PH} \leq 5$ is the hexa-aquo $\left[\mathrm{Al}\left(\mathrm{H}_{2} \mathrm{O}\right)^{6}\right]^{3+}$. And new mononuclear species reported as $\left[\mathrm{Al}(\mathrm{OH})_{2}\right]^{+}$and $[\mathrm{Al}(\mathrm{OH})]^{2+}$ are formed by deprotonation of water molecules as the $\mathrm{PH}$ increases or the soluble neutral species $\mathrm{Al}(\mathrm{OH})_{3}$ neglects the coordinated water molecules. In addition, polynuclear species $\left[\mathrm{Al}_{2}(\mathrm{OH})_{2}\right]^{4+}$ and $\left[\mathrm{Al}_{3}(\mathrm{OH})_{3}\right]^{5+}$ are also formed depending on time and total aluminium concentration(Rubini et al. 2002). Therefore, to describe the solution chemical properties of aluminium in biological systems, it is necessary to consider the soluble and insoluble forms of hydroxy-oxygen complexes and the morphological equilibrium of complexes formed with other competing ligands (Crisponi et al. 2011). On the other hand, cell culture types may just differ in susceptibility to Al. For example, different degree of cell viability impairment was significantly related to the composition of cell membrane(Cecchi et al. 2005). The composition of membrane lipids is an important factor affecting the interaction between foreign substances and cells itself, and the resulting cell membrane disturbance is a key step in early cell death(Butterfield 2002). After crossing the cell membrane, the redox status and calcium ion levels of different cells are closely related to the susceptibility of cells to foreign poisons(Stefani and Dobson 2003). In this study, compared with the control group, the groups treated with increasing APS concentrations exhibited decreasing proportions of normal cells and gradually increasing proportions of early apoptotic cells, late apoptotic cells and dead cells. Consistent with previous findings on aluminium-induced splenic lymphocyte apoptosis (Zhuang et al. 2016), these changes indicate that aluminium induced SF9 cell apoptosis in a dose-dependent manner.

KEGG enrichment analysis of transcriptome results showed that the downregulated genes were mostly involved in the longevity regulation pathway, the PI3K-Akt signalling pathway, and protein processing in the endoplasmic reticulum. Among the upregulated genes, most genes were involved in pathways associated with the metabolism of CYP, the metabolism of glutathione, and the metabolism of xenobiotics by CYP.

Mammalian target of rapamycin (mTOR) is a serine/threonine protein kinase in the PI3K-related kinase (PIKK) family and plays important roles in cell growth, proliferation, survival and cell cycle regulation. mTOR forms the catalytic subunit of at least two functionally distinct protein complexes, mTOR complex 1 (mTORC1) and mTOR complex 2 (mTORC2). mTORC1 consists of four parts: mTOR, regulatory-associated protein of mTOR (RAPTOR), GßL (mammalian lethal Sec13 protein 8, mLST8), and rapamycin-FKBP12 (Foster and Fingar 2010; Kim et al. 2003; Saxton and Sabatini 2017; Zhang et al. 2000). mTORC1 plays a key role in regulating cell growth, thus controlling the balance between anabolism and catabolism to enable cells to adapt to environmental conditions. It can promote efficient protein synthesis through the phosphorylation of p70S6 kinase 1 (S6K1) on its hydrophobic motif site and elF4E Binding Protein (4EBP) at multiple sites (Gingras et al. 1999; Holz et al. 2005). The 
mTORC1 signal can regulate mRNA translation and most profoundly affects mRNA containing pyrimidines, including the mRNA of most of the genes involved in protein synthesis (Hsieh et al. 2012; Thoreen et al. 2012). RAPTOR, an mTOR binding protein in mTORC1 with a molecular weight of $150 \mathrm{kDa}$, contains multiple WD repeats. As a scaffold protein, it plays a pivotal role in the mTOR signalling pathway (Hara et al. 2002; Kim et al. 2002) and related mTOR pathways, such as the PI3K-Akt signalling pathway and the longevity regulating pathway. In our transcriptome results, RAPTOR gene expression was downregulated, which also influenced the function of mTORC1. The mechanistic target of mTOR coordinates cell growth and metabolism with nutrients and other environmental inputs. Aluminium ions have strong binding ability with amino acids and proteins (Dudev et al. 2018; Fan et al. 2010), which may inhibit the amino acid-sensitive mTOR pathway. The decreased level of RAPTOR weakens the phosphorylation of S6K1, further affects protein synthesis and inhibits cell growth(Kim et al. 2002). Moreover, musclespecific RAPTOR or mTOR knockout mice show muscle atrophy and weight loss leading to early death(Risson et al. 2009). On the other hand, many studies have shown that inhibition of mTOR can promote autophagy and prolong life(Roczniak-Ferguson et al. 2012; Settembre et al. 2012). Here, autophagy could be a result of disrupted apoptotic machinery. However, for biological growth process, growth promotion should be the main line of regulation, and autophagy should be used as a compensation pathway to regulate abnormal growth and metabolism.

RAPTOR/mTORC1 loss mice have normal white adipose tissue for the first several weeks of life, but lipodystrophy associated with hepatomegaly, hepatic steatosis and insulin intolerance soon developed(Lee et al. 2016). This indicates that the early inhibition of mTOR pathway may be helpful to cell health, but the continuous inhibition, coupled with the continuous deterioration of the nutritional environment, will eventually lead to cell damage and apoptosis. Excessive autophagy also shortened cell life, leading to death as the concentration of aluminium ions increased. Although autophagy and apoptosis are different forms of programmed cell death, many studies have specifically focused on the cross-talk that occurs between autophagy and apoptosis to understand how these two types of cell death are related to each other(Green et al. 2011; Noguchi et al. 2014). For example, Atg5, which is known to induce autophagy, converts autophagy to apoptosis through calpain-mediated cleavage(Rubinstein et al. 2011).

In addition, we found that the expression of Ptdlns-dependent protein kinase-1 (PDPK1) and some small heat shock proteins (HSPs), including heat shock $70 \mathrm{kDa}$ protein (HSPA1s or Hsp70s) and crystallin alpha B (CRYAB), was downregulated. PDPK1 is an important protein in the PI3KAkt signalling pathway, which is related to cell proliferation and survival processes (Nicholson and Anderson 2002). The PI3K-Akt-mTOR pathway also affects protein synthesis (Ekizceli et al. 2017; Kenessey and Ojamaa 2006), which may be related to PDPK1 phosphorylation and activation of Akt and S6K1 (Avruch et al. 2001).Downregulation of PDPK1 expression could inhibit the phosphorylation of downstream signals, thus inhibiting cell proliferation and protein synthesis. Especially in the research of tumor inhibition, PDPK1 is often used as a potential therapeutic target to inhibit the proliferation of cancer cells by inhibiting its expression (Zhang and Yu 2019; Zhang and Zhong 2020). CRYAB is implicated in cell apoptosis by negatively regulating the activity of caspase-3 to promote or inhibit apoptosis. Downregulation of CRYAB protein expression showed enhanced apoptosis, accompanied by an increase in Caspase-3 (Kamradt and M. 2002; Stegh et al. 2008). On the other hand, the 70-kDa heat shock proteins (HSPA1s) are ubiquitous molecular chaperones that plays an active role in the folding and remodeling of various cellular proteins, and are also regulated by PI3K-Akt signalling pathway(Lulu et al. 2019). They act at almost all stages of a protein's life, from synthesis to degradation, and are essential for maintaining protein homeostasis(Balchin et al. 2016; Imamoglu et al. 2020; Rosenzweig et al. 2019).

In animal cells, glutathione (GSH, y-glutamyl-cysteinyl-glycine) is the most abundant low-molecular weight thiol, most of which is present in the cytosol. GSH/GSH disulfide (GSSG) is a major redox couple (Jones 2002) that plays crucial roles in nutrient metabolism, antioxidant defence, and other essential pathways. GSH metabolism is an important process in ageing and many other diseases (including Parkinson's disease, Alzheimer's disease, cancer, and liver disease) (Guoyao et al. 2004). In our study, GSH metabolism was identified as one of the pathways associated with many differentially expressed genes, mainly GSH transferase genes, including GSH S-transferase (GST), prostaglandin-H2 Disomerase (HPGDS) and pyrimidodiazepine synthase (SE). The GST superfamily is a superfamily of multifunctional proteins that play fundamental roles in the cellular detoxification of exogenous and endogenous compounds. The main method for detoxification involves the catalysis of the binding of GSH with compounds that have an electrophilic centre to form nontoxic derivatives (Coleman et al. 1997; Frova 2006). After entering the cell, aluminium ions will form complexes with biomolecules, and proteins are the main targets. In the blood, for example, transferrin is the primary binding agent (Wróbel et al. 1995). Aluminium ions can induce the formation of backbone ring structures in a variety of peptide structures through simultaneous bonds with oxygen and nitrogen atoms. These ring structures lead to irreversible denaturation of proteins and destabilization of the proteins (Song et al. 2014). Meanwhile, aluminium can induce the formation of oxygen free radicals, which leads to oxidative damage of mitochondria through the production of reactive oxygen species (ROS) and the accumulation of iron, thus leading to the internal apoptosis of cells (Willhite et al. 2014; Wu et al. 2012; Yu et al. 2019). Aconitase is a key enzyme in mitochondria, and aluminium can also induce mitochondrial dysfunction by decreasing the activity of aconitase through increased oxidative stress or Fe-S cluster perturbation(Kumar et al. 2009; Middaugh et al. 2005). In our study, aluminium ions cause overexpression of GSTS, HPGDS and SE. These changes affect the biological functions of GSH, thus improving the sensitivity of TNF-induced apoptosis and decreasing the GSH/GSSG ratio, which is associated with inhibition of nuclear factor-kappaB (NF-kb) transactivation(Matsumaru et al. 2003). The mode of cell death includes increased cathepsin activity and the release of cytochrome $\mathrm{C}(\mathrm{CYC})$ in mitochondria, and GSH regulation is one of the necessary conditions for CYC to promote apoptosis (Brown and Borutaite 2008). In this study, many upregulated DEGs are associated with CYP-related pathways. The main CYP system is the microsomal P450 system. CYP is a superfamily of monooxygenases and predominantly localized in endoplasmic reticulum membranes, where they metabolize all kinds of xenobiotic and endogenous compounds. CYPs are also present in subcellular 
compartments such as plasma membrane and mitochondria(Ahn and Yun 2010). Many xenobiotic inducers can induce the uncoupling of CYP and catalyze the cyclic production of ROS, leading to multiple toxic effects(Zangar et al. 2004). Here, aluminium, as an exogenous substance, may be involved in the above pathway, leading to cell apoptosis. Several studies have also shown that exposure to aluminium inhibits the CYP system(Cao et al. 2020; Zhu et al. 2013).

\section{Conclusion}

In this study, through cell morphology, viability curve and apoptosis analyses, we found that high concentrations of aluminium alter cell morphology, reduce cell vitality, and cause apoptosis. Through RNA-Seq transcriptomics, we found that aluminium ions may inhibit the expression of RAPTOR, PDPK1囚and small HSPs (CRYAB and HSPA1s), leading to changes in mTOR-related pathways (such as the longevity regulation pathway and the PI3k-AKT signalling pathway), and promoting cell apoptosis. On the other hand, aluminium ions lead to the overexpression of GST囚HPGDS and SE, and induce intracellular oxidative damage, which ultimately affects cell growth and apoptosis through a series of cascade reactions. What's more, many upregulated DEGs are associated with CYP-related pathways, which show that aluminium may induce the uncoupling of CYP and catalyze the cyclic production of ROS, leading to multiple toxic effects. Given these findings, we propose a hypothetical model for how aluminium induces cell apoptosis (Figure 12), which will help us to further understand the biological mechanism of action of aluminium.

\section{Declarations}

\section{Ethics approval:}

This article does not contain any studies with human or animal subjects.

This article does not contain clinical trials.

Consent to Participate: there is no human research in this study.

Consent to Publish: there is no human research in this study.

Data availability: all data generated during the study are appear in the submitted article (and its supplementary information files).

Plant Reproducibility: These experiments have good reproducibility.

\section{Acknowledgements}

This research was financially supported by the National Natural Science Foundation of China [Grant number 31802140冈31572467囚 31861143051]

\section{Author Contributions}

Keping Chen performed the conception and design of the study. Rong Feng collected the test data, analyzed the data, and drafted the manuscript. Liang Chen helped perform the analysis with constructive discussions.

\section{Conflict of interest}

The authors declare no conflict of interest.

\section{References}

1. Ahn T, Yun $\mathrm{CH}$ (2010) Molecular mechanisms regulating the mitochondrial targeting of microsomal cytochrome P450 enzymes Current drug metabolism 11:830-838 doi:10.2174/138920010794479655

2. Altschul SF (2012) Basic local alignment search tool (BLAST) Journal of Molecular Biology 215:403-410

3. Avruch J, Belham C, Weng QP, Hara K, Yonezawa K (2001) The p70 S6 Kinase Integrates Nutrient and Growth Signals to Control Translational Capacity Prog Mol Subcell Biol 26:115-154

4. Balchin D, Hayer-Hartl M, Hartl FU (2016) In vivo aspects of protein folding and quality control Science 353:aac4354

5. Bondy SC (2010) The neurotoxicity of environmental aluminum is still an issue Neurotoxicology 31:575-581

6. Brown GC, Borutaite V (2008) Regulation of apoptosis by the redox state of cytochrome c Biochim Biophys Acta 1777:877-881

7. Butterfield VMAA (2002) Role of glycine-33 and methionine-35 in Alzheimer's amyloid $\beta$-peptide 1-42-associated oxidative stress and neurotoxicity Biochimica Et Biophysica Acta冈molecular Basis of Disease 1586:0-198 
8. Cao C, Li X, Fu Q, Wang K, Li X (2020) Selenium-Rich-Yeast Protects Against Aluminum-Induced Activating Nuclear Xenobiotic Receptors and Triggering Inflammation and Cytochromes P450 Systems in Mice Heart Biological trace element research 194:244-250

9. Cecchi C et al. (2005) Insights into the molecular basis of the differing susceptibility of varying cell types to the toxicity of amyloid aggregates J Cell Sci 118:3459-3470 doi:10.1242/jcs.02473

10. Chen TJ, Cheng HM, Wang DC, Hung HS (2011) Nonlethal aluminum maltolate can reduce brain-derived neurotrophic factor-induced Arc expression through interrupting the ERK signaling in SH-SY5Y neuroblastoma cells Toxicology Letters 200:67-76

11. Coleman J, Blake-Kalff M, Davies E (1997) Detoxification of xenobiotics by plants: chemical modification and vacuolar compartmentation Trends in Plant Science 2:144-151

12. Crisponi G, Nurchi VM, Bertolasi V, Remelli M, Faa G (2012) Chelating agents for human diseases related to aluminium overload Coordination Chemistry Reviews 256:89-104

13. Crisponi G, Nurchi VM, Faa G, Remelli M (2011) Chemlnform Abstract: Human Diseases Related to Aluminum Overload Cheminform 42:no-no

14. Dudev T, Cheshmedzhieva D, Doudeva L (2018) Competition between abiogenic Al3+ and native Mg2+, Fe2+ and Zn2+ ions in protein binding sites: implications for aluminum toxicity Journal of Molecular Modeling 24:55

15. Ekizceli G, Inan S, Oktem G, Onur E, Ozbilgin K (2017) Assessment of mTOR pathway molecules during implantation in rats Biotechnic \& Histochemistry 92:1-9

16. Fan JF, He LJ, Liu J, Tang M (2010) Investigation on the micro-mechanisms of $\mathrm{Al}(3+)$ interfering the reactivities of aspartic acid and its biological processes with $\mathrm{Mg}(2+)$ Journal of Molecular Modeling 16:1639-1650

17. Foglio E, Buffoli B, Exley C, Rezzani R, Rodella LF (2012) Regular consumption of a silicic acid-rich water prevents aluminium-induced alterations of nitrergic neurons in mouse brain: histochemical and immunohistochemical studies Histology \& Histopathology 27:1055

18. Foster KG, Fingar DC (2010) Mammalian Target of Rapamycin (mTOR): Conducting the Cellular Signaling Symphony * Journal of Biological Chemistry 285

19. Frova C (2006) Glutathione transferases in the genomics era: new insights and perspectives Biomolecular Engineering 23:149-169

20. Gingras AC et al. (1999) Regulation of 4E-BP1 phosphorylation: a novel two-step mechanism Genes Dev 13:1422-1437

21. Green DR, Galluzzi L, Kroemer G (2011) Mitochondria and the Autophagy-Inflammation-Cell Death Axis in Organismal Aging Science 333:1109-1112

22. Guoyao W, Yun-Zhong F, Sheng Y, Lupton JR, Turner ND (2004) Glutathione metabolism and its implications for health Journal of Nutrition $134: 489$

23. Hara K et al. (2002) Raptor, a binding partner of target of rapamycin (TOR), mediates TOR action Cell 110:177-189

24. Hirata-Koizumi M, Fujii S, Ono A, Hirose A, Nishikawa A (2011) Evaluation of the reproductive and developmental toxicity of aluminium ammonium sulfate in a two-generation study in rats Food \& Chemical Toxicology 49:1948-1959

25. Holz MK, Ballif BA, Gygi SP, Blenis J (2005) mTOR and S6K1 Mediate Assembly of the Translation Preinitiation Complex through Dynamic Protein Interchange and Ordered Phosphorylation Events Cell 123:569-580

26. Hsieh AC et al. (2012) The translational landscape of mTOR signalling steers cancer initiation and metastasis Nature 485:55

27. Imamoglu R, Balchin D, Hayer-Hartl M, Hartl FU (2020) Bacterial Hsp70 resolves misfolded states and accelerates productive folding of a multi-domain protein Nature Communications 11:365

28. Jones DP (2002) Redox potential of GSH/GSSG couple: assay and biological significance Methods in Enzymology 348:93-112

29. Kamradt, M. C (2002) The small heat shock protein alpha B-crystallin negatively regulates apoptosis during myogenic differentiation by inhibiting caspase-3 activation Journal of Biological Chemistry 277:38731-38736

30. Kanehisa M et al. (2008) KEGG for linking genomes to life and the environment Nucleic Acids Res 36:D480-484 doi:10.1093/nar/gkm882

31. Kenessey A, Ojamaa K (2006) Thyroid hormone stimulates protein synthesis in the cardiomyocyte by activating the Akt-mTOR and p70S6K pathways Journal of Biological Chemistry 281:20666

32. Kijak E, Rosato E, Knapczyk K, Pyza E (2014) Drosophila melanogaster as a model system of aluminum toxicity and aging Insect science 21:189-202 doi:10.1111/1744-7917.12017

33. Kim DH et al. (2002) mTOR Interacts with Raptor to Form a Nutrient-Sensitive Complex that Signals to the Cell Growth Machinery Cell 110:163-175

34. Kim DH, Sm SDD, Latek RR, Guntur KV, Erdjument BH, Tempst P, Sabatini DM (2003) GbetaL, a positive regulator of the rapamycin-sensitive pathway required for the nutrient-sensitive interaction between raptor and mTOR Molecular Cell 11:895-904

35. Kumar V, Bal A, Gill KD (2009) Susceptibility of mitochondrial superoxide dismutase to aluminium induced oxidative damage Toxicology 255:117-123 doi:10.1016/j.tox.2008.10.009

36. Langmead B, Salzberg SL (2012) Fast gapped-read alignment with Bowtie 2 Nature Methods 
37. Lee PL, Tang Y, Li H, Guertin DA (2016) Raptor/mTORC1 loss in adipocytes causes progressive lipodystrophy and fatty liver disease Molecular Metabolism 5:422-432

38. Li X, Hu C, Zhu Y, Sun H, Li Y, Zhang Z (2011) Effects of Aluminum Exposure on Bone Mineral Density, Mineral, and Trace Elements in Rats Biological trace element research 143:378-385

39. Liu L et al. (2018) Aluminum toxicity related to SOD and expression of presenilin and CREB in Bombyx mori Archives of Insect Biochemistry \& Physiology:e21480-

40. Lulu et al. (2019) Overexpressed Hsp70 alleviated formaldehyde-induced apoptosis partly via PI3K/Akt signaling pathway in human bronchial epithelial cells Environmental Toxicology

41. Matsumaru K, Ji C, Kaplowitz N (2003) Mechanisms for sensitization to TNF-induced apoptosis by acute glutathione depletion in murine hepatocytes Hepatology 37:1425-1434

42. Middaugh J, Hamel R, Jean-Baptiste G, Beriault R, Chenier D, Appanna VD (2005) Aluminum triggers decreased aconitase activity via Fe-S cluster disruption and the overexpression of isocitrate dehydrogenase and isocitrate lyase: a metabolic network mediating cellular survival The Journal of biological chemistry 280:3159-3165 doi:10.1074/jbc.M411979200

43. Nicholson KM, Anderson NG (2002) The protein kinase B/Akt signalling pathway in human malignancy Cellular Signalling 14:381-395

44. Noguchi M, Hirata N, Suizu F (2014) The links between AKT and two intracellular proteolytic cascades: Ubiquitination and autophagy Biochimica et Biophysica Acta (BBA) - Reviews on Cancer 1846:342-352

45. Paz LNF et al. (2017) Evaluation of in vivo and in vitro toxicological and genotoxic potential of aluminum chloride Chemosphere 175:130137 doi:10.1016/j.chemosphere.2017.02.011

46. Risson V et al. (2009) Muscle inactivation of mTOR causes metabolic and dystrophin defects leading to severe myopathy Journal of Cell Biology 187:859-874

47. Roberts A, Pachter $L$ (2013) Streaming fragment assignment for real-time analysis of sequencing experiments Nature Methods 10:71-U99

48. Roczniak-Ferguson A et al. (2012) The Transcription Factor TFEB Links mTORC1 Signaling to Transcriptional Control of Lysosome Homeostasis Science Signaling 5:ra42

49. Rosenzweig R, Nillegoda NB, Mayer MP, Bukau B (2019) The Hsp70 chaperone network Nature Reviews Molecular Cell Biology 20:665-680

50. Rubini P, Lakatos A, Champmartin D, Kiss T (2002) Speciation and structural aspects of interactions of Al(III) with small biomolecules Coordination Chemistry Reviews 228:137-152 doi:https://doi.org/10.1016/S0010-8545(01)00467-2

51. Rubinstein Assaf D, Eisenstein M, Ber Y, Bialik S, Kimchi A (2011) The autophagy protein Atg12 associates with antiapoptotic Bcl-2 family members to promote mitochondrial apoptosis Molecular Cell 44:698-709

52. Santos EJD, Zagonel GF, Herrmann AB, Fantin EB, Sturgeon RE (2018) Determination of aluminium phosphide (AIP) in fumigants by ICP OES Analytical Methods 10

53. Saxton RA, Sabatini DM (2017) mTOR Signaling in Growth, Metabolism, and Disease Cell 168:960-976

54. Settembre C et al. (2012) A lysosome-to-nucleus signalling mechanism senses and regulates the lysosome via mTOR and TFEB The EMBO journal 31:1095-1108 doi:10.1038/emboj.2012.32

55. Shrivastava S (2012) Combined effect of HEDTA and selenium against aluminum induced oxidative stress in rat brain J Trace Elem Med Biol 26:210-214

56. Song B et al. (2014) Frontispiece: Irreversible Denaturation of Proteins through Aluminum-Induced Formation of Backbone Ring Structures Angewandte Chemie 53:6358-6363

57. Sood PK, Nahar U, Nehru B (2012) Stress Proteins and Glial Cell Functions During Chronic Aluminium Exposures: Protective Role of Curcumin Neurochemical Research 37:639-646

58. Stefani M, Dobson C (2003) Protein aggregation and aggregate toxicity: new insights into protein folding, misfolding diseases and biological evolution Journal of Molecular Medicine 81:678-699

59. Stegh AH et al. (2008) Bcl2L12-mediated inhibition of effector caspase-3 and caspase-7 via distinct mechanisms in glioblastoma Proceedings of the National Academy of Sciences 105:10703-10708

60. Sun Q, Clark JM, Park Y (2017) Environmental pollutants and type 2 diabetes: a review of human studies Toxicological \& Environmental Chemistry 99:1283-1303

61. Sun ZZ, Chen ZB, Jiang H, Li LL, Li EG, Xu Y (2009) Alteration of A metabolism-related molecules in predementia induced by AICl3 and d galactose AGE 31:277-284

62. Thoreen CC, Chantranupong L, Keys HR, Wang T, Gray NS, Sabatini DM (2012) A unifying model for mTORC1-mediated regulation of mRNA translation Nature 485:109 doi:10.1038/nature11083

63. https://www.nature.com/articles/nature11083\#supplementary-information 
64. Trapnell C et al. (2010) Transcript assembly and quantification by RNA-Seq reveals unannotated transcripts and isoform switching during cell differentiation Nature Biotechnology 28:511-515 doi:10.1038/nbt.1621

65. Wielkopolan B, Obrępalska-Stęplowska A (2016) Three-way interaction among plants, bacteria, and coleopteran insects Planta 244:313-332

66. Willhite CC et al. (2014) Systematic review of potential health risks posed by pharmaceutical, occupational and consumer exposures to metallic and nanoscale aluminum, aluminum oxides, aluminum hydroxide and its soluble salts Critical Reviews in Toxicology 44 Suppl 4:1

67. Witters H, Vangenechten JH, Van Puymbroeck S, Vanderborght OL (1984) Interference of aluminum and pH on the Na-influx in an aquatic insect Corixa punctata (Illig.) Bulletin of environmental contamination and toxicology 32:575-579 doi:10.1007/bf01607540

68. Wróbel K, González EB, Sanz-Medel A (1995) Aluminium and silicon speciation in human serum by lon-exchange high-performance liquid chromatography-electrothermal atomic absorption spectrometry and gel electrophoresis Analyst 120:809-815 doi:10.1039/an9952000809

69. Wu Z, Du Y, Xue H, Wu Y, Zhou B (2012) Aluminum induces neurodegeneration and its toxicity arises from increased iron accumulation and reactive oxygen species (ROS) production Neurobiology of Aging 33:199.e191-199.e112

70. Yu L, Wu J, Zhai Q, Tian F, Chen W (2019) Metabolomic analysis reveals the mechanism of aluminum cytotoxicity in HT-29 cells PeerJ $7: e 7524$

71. Zangar RC, Davydov DR, Verma S (2004) Mechanisms that regulate production of reactive oxygen species by cytochrome P450 Toxicology \& Applied Pharmacology 199:316-331

72. Zhang H, Stallock JP, Ng JC, Reinhard C, Neufeld TP (2000) Regulation of cellular growth by the Drosophila target of rapamycin dTOR Genes Dev 14:2712-2724 doi:10.1101/gad.835000

73. Zhang H, Zhang JY, Wang HL, Luo PJ, Zhang JB (2016) The Revision of Aluminum-containing Food Additive Provisions in China Biomedical and environmental sciences : BES 29:461-466 doi:10.3967/bes2016.061

74. Zhang QL et al. (2010) Bax gene silencing: a potential intervention in aluminum-induced neural cell death J Biol Regul Homeost Agents 24:717

75. Zhang X, Yu Z (2019) Expression of PDK1 in malignant pheochromocytoma as a new promising potential therapeutic target Clinical \& Translational Oncology 21:1312-1318

76. Zhang X, Zhong S (2020) PDK1 Inhibitor GSK-470 Exhibits Potent Anticancer Activity in a Pheochromocytoma PC12 Cell Tumor Model via Akt/mTOR Pathway Anti-cancer agents in medicinal chemistry 20:828-833 doi:10.2174/1871520620666200318100701

77. Zhou SL, Liu SJ, Jiang XY, Chen GH, Cao C, Liu FY, Chen XQ (2010) Determination of four additives in aluminum electrolyte by ICP-OES with wet digestion Microchemical Journal 96:412-414

78. Zhu Y, Han Y, Zhao H, Li J, Hu C, Li Y, Zhang Z (2013) Suppressive effect of accumulated aluminum trichloride on the hepatic microsomal cytochrome P450 enzyme system in rats Food and chemical toxicology : an international journal published for the British Industrial Biological Research Association 51:210-214 doi:10.1016/j.fct.2012.09.035

79. Zhuang C, Huo H, Fu W, Huang W, Han L, Song M, Li Y (2016) Aluminum chloride induced splenic lymphocytes apoptosis through NF-KB inhibition Chemico-Biological Interactions 257:94-100

\section{Figures}

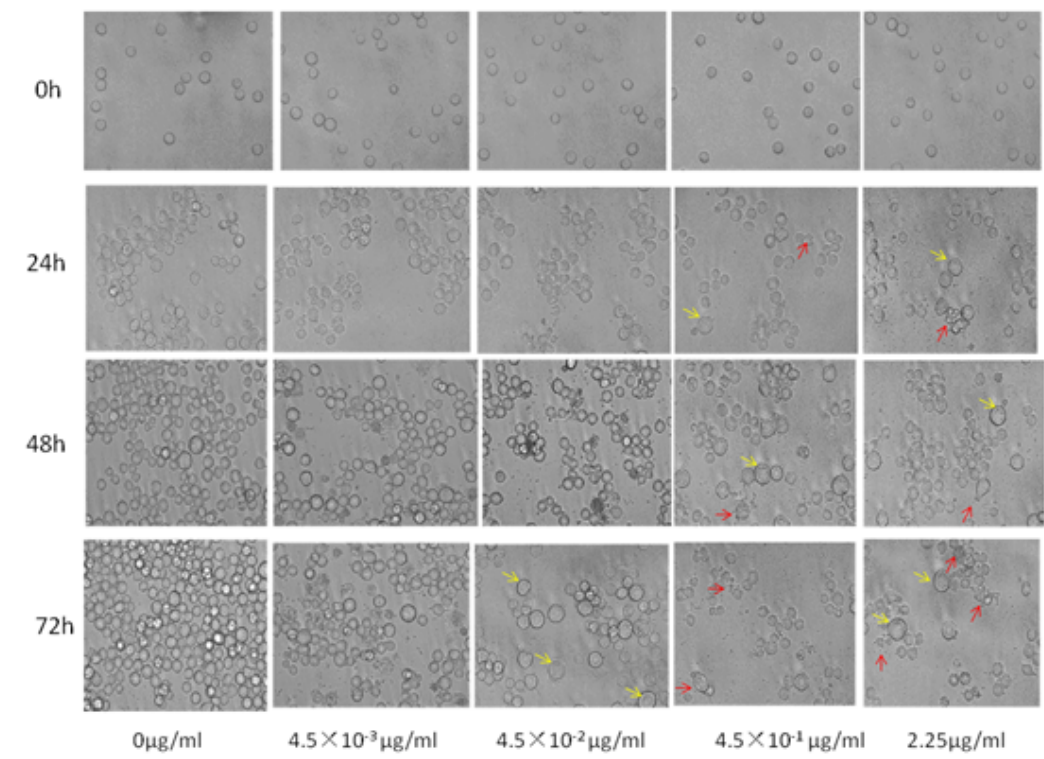

Page $11 / 17$ 


\section{Figure 1}

Morphological changes of sf9 cells. Sf9 cells were treated with different concentrations of APS $(0,4.5 \times 10-3,4.5 \times 10-2,4.5 \times 10-1,2.25 \mu \mathrm{g} / \mathrm{ml})$ for 0h, 24h, 48h, 72h. Compared with the control group, cell morphology was changed with the increase of APS treatment concentration and time. The yellow arrows indicate enlarged cells and the red arrows indicate broken membranes with contents flowing out. Magnification: $400 \times$.

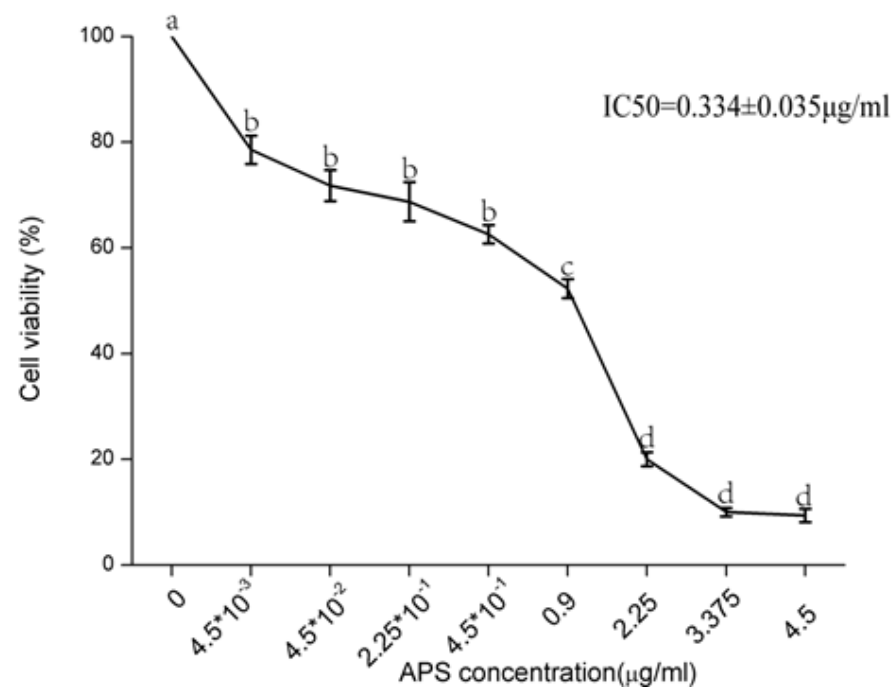

Figure 2

Changes of sf9 cell viability. Sf9 cells were treated with different APS concentrations for $72 \mathrm{~h}$ and cell viability was detected by CCK-8 assay. Six replicates were set in the experiment and results are shown as the mean \pm SD. One-way ANOVA was used for significance analysis. a, b, $c$ and $d$ indicated significant differences, with $\mathrm{p}<0.05$. The $\mathrm{X}$-axis represents the different aluminum content, and the $\mathrm{Y}$-axis represents the percentage of cell vitality.

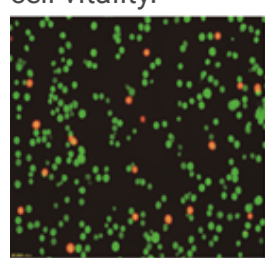

$0 \mu \mathrm{g} / \mathrm{ml}$

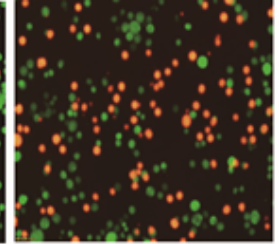

$4.5 \times 10^{-3} \mu \mathrm{g} / \mathrm{ml}$

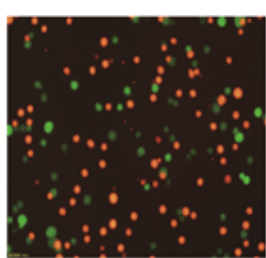

$4.5 \times 10^{-2} \mu \mathrm{g} / \mathrm{ml}$

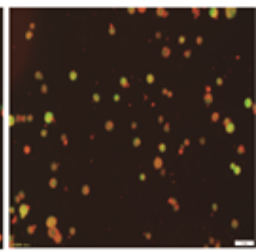

$4.5 \times 10^{-1} \mu \mathrm{g} / \mathrm{ml}$

\section{Figure 3}

Morphological apoptosis of sf9 cells. Sf9 cells were treated with APS at different concentrations for $72 \mathrm{~h}$, and morphological apoptosis was detected by AO/EB kit. The results showed that the rate of damaged cells increased with the increase of APS concentration. And the cells proliferation was also inhibited. Magnification: 400x.
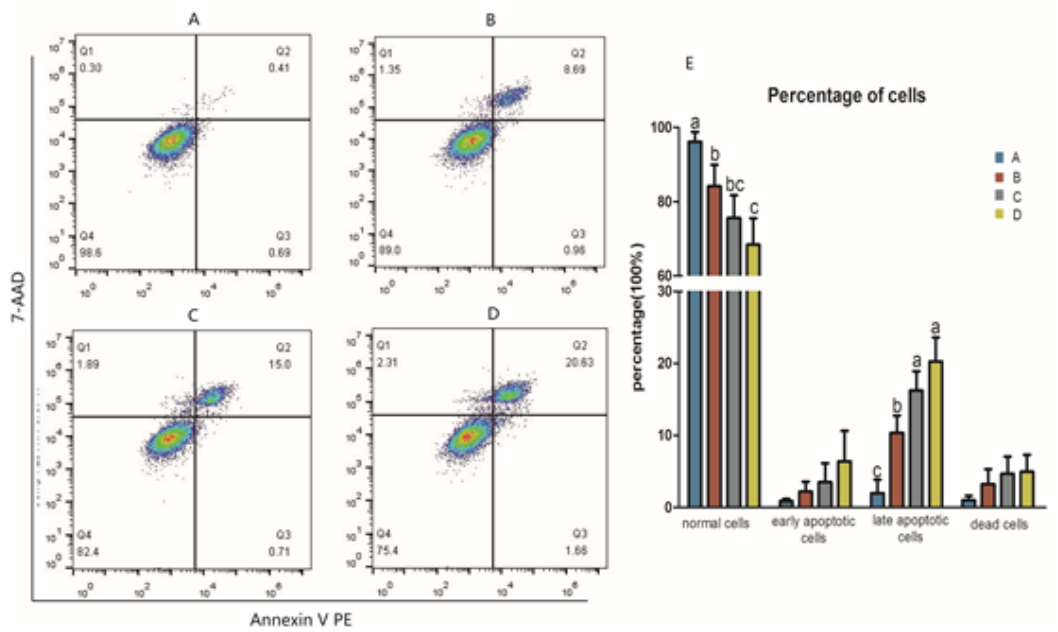

\section{Figure 4}


APS induces apoptosis in sf9 cells. Cells were treated with different concentrations of APS (A:0 $\mu \mathrm{g} / \mathrm{ml}, \mathrm{B}: 4.5 \times 10-3 \mu \mathrm{g} / \mathrm{ml}, \mathrm{C}: 4.5 \times 10-2 \mu \mathrm{g} / \mathrm{ml}$, $\mathrm{D}: 4.5 \times 10-1 \mu \mathrm{g} / \mathrm{ml}$ ) for 72h, and apoptosis was detected by flow cytometry using annexin-v-pe / 7-aad staining. Q1: dead cells; Q2: late apoptosis cells, Q3: early apoptosis cells, Q4: normal cells. E: The percentage of cells in each apoptotic cycle after treatment with different concentrations of aluminum. One-way ANOVA was used for significance analysis. a, b and c indicated significant differences, with $p<0.05$. Repeat three times.

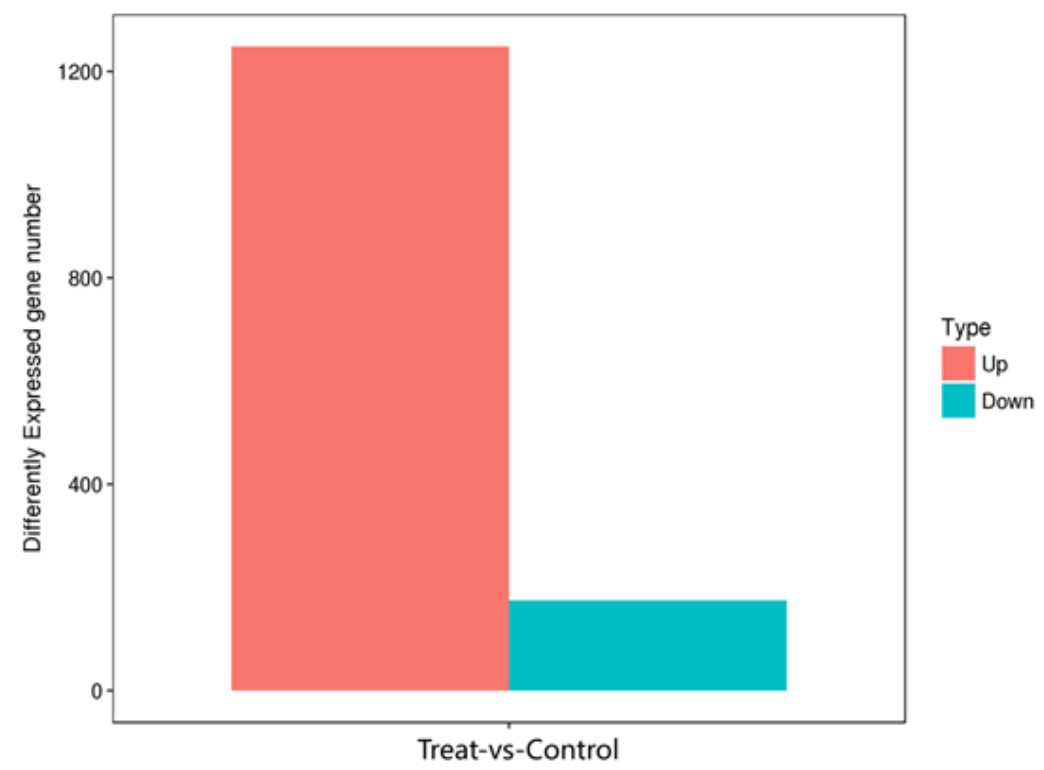

\section{Figure 5}

Statistic of Differently Expressed gene. Here the red is the up-regulated gene, and the blue is the down-regulated gene. DESeq software was used to standardize the counts of unigene in each sample (Basemean value was used to estimate the expression level), calculate the difference multiple, and test the difference significance of reads by NB (negative binomial distribution test). Finally, screen the differentially expressed unigene according to the difference multiple and difference significance test results. The criteria for screening differences were $p<0.05$ and the difference multiple is greater than 2 .

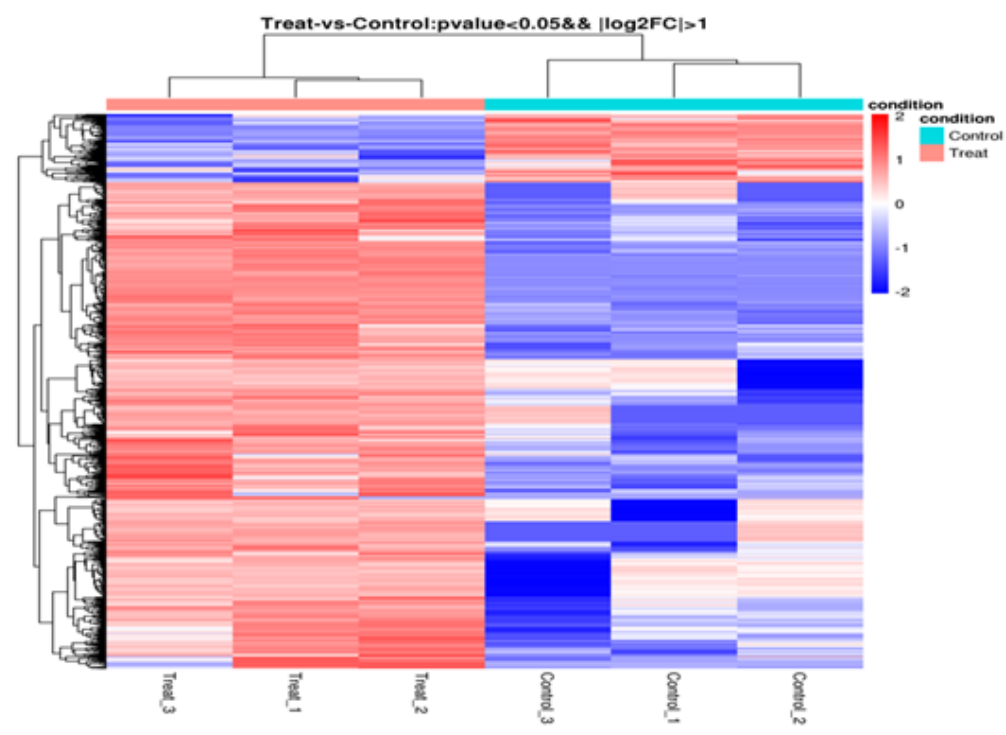

Figure 6

Clustering diagram of each difference grouping. Red indicates high expression of unigene, blue indicates low expression of unigene. Unsupervised hierarchical clustering was performed for differentially expressed unigene. The phylogenetic trees on the left of the chart indicate multiple samples of the distance between two calculation, a distance matrix, two recent merger distance for the new class, calculating the distance between new class and the current various, merger, calculate again, until only a class, in general, the same sample by clustering appeared in the same cluster, gathered in the same cluster in unigene may have similar biological function. The phylogenetic trees on the top of 
the chart indicate a pairwise comparison of significant differences in clustering analysis of differential gene expression levels between the treatment group and the control group.
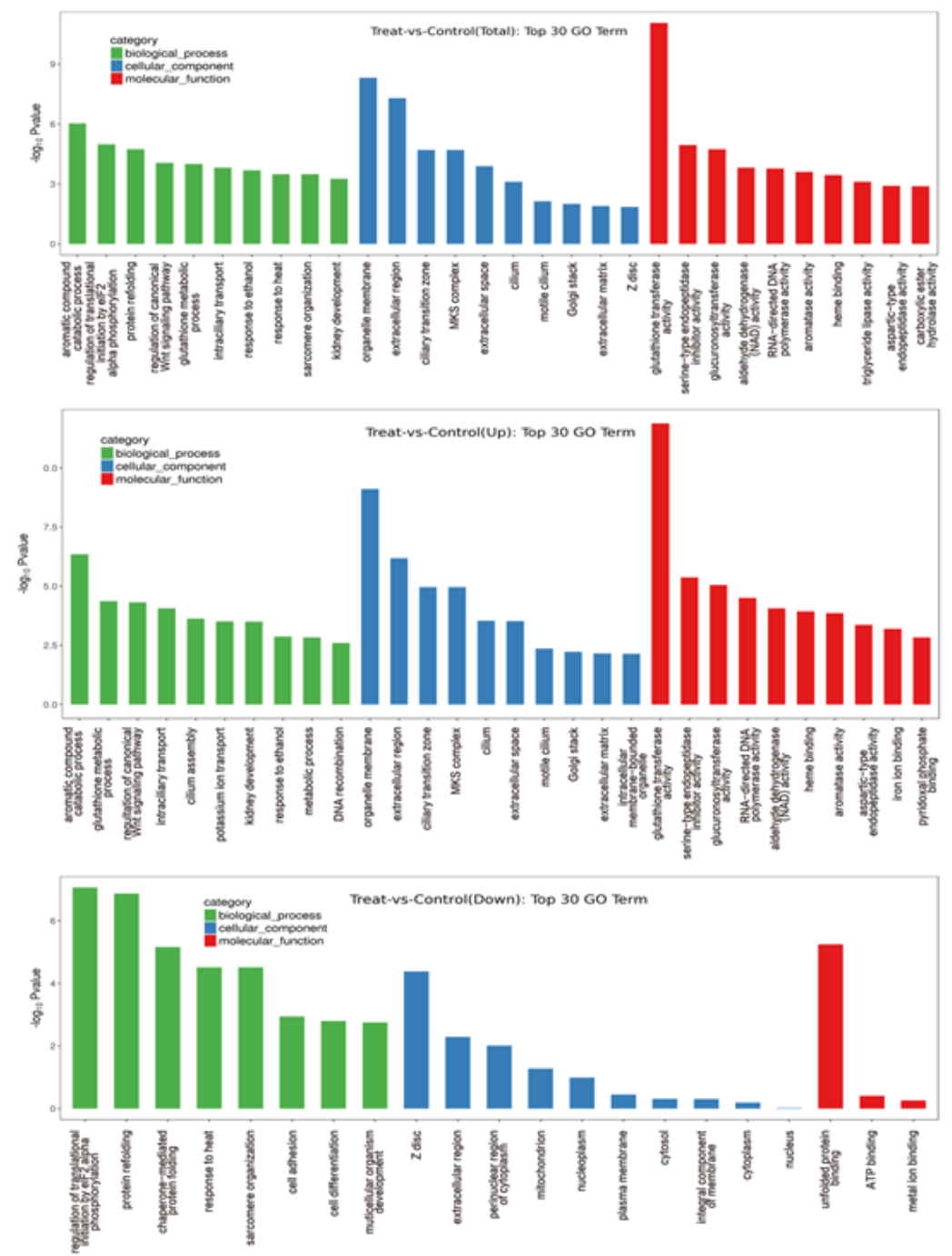

Figure 7

GO enriched the top30 items graph. After the differentially expressed unigene was obtained, GO enrichment analysis was performed on differentially expressed unigene to describe its function (combined with GO annotation results). The number of differential mRNAs included in each GO item was counted, and the significance of differential unigene enrichment in each GO item was calculated by hypergeometric distribution test. The calculated results will return a $p$ value of enrichment significance, with a small $p$ value indicating enrichment of differential unigene in the $\mathrm{GO}$ entry. As shown in the figure, $\mathrm{GO}$ items corresponding to the number of different unigene greater than 2 in the three classifications were screened, and 10 items were sorted from large to small according to the -log10pvalue corresponding to each item. The X-axis is the $\mathrm{GO}$ entry name, and the $\mathrm{Y}$-axis is -log10pvalue. 

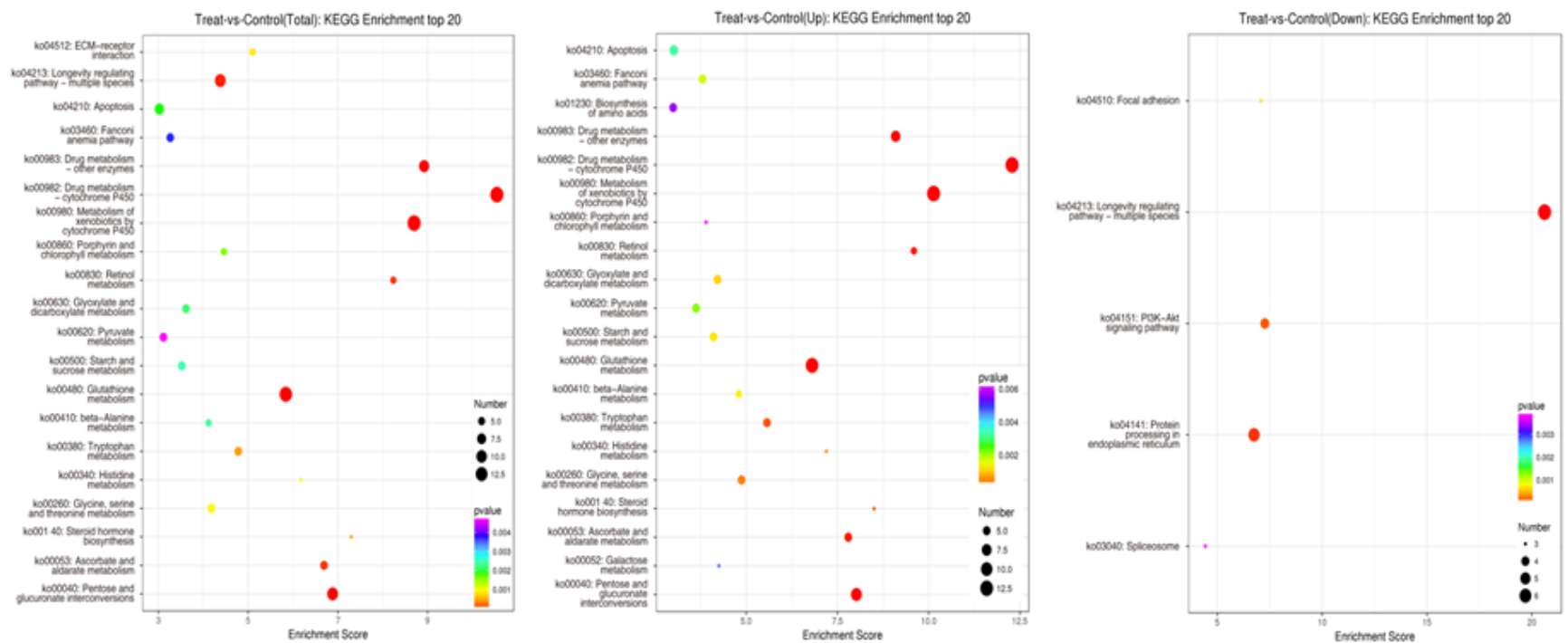

Figure 8

KEGG enrichment bubble map (top 20). KEGG database was used for pathway analysis of differential unigene (combined with KEGG annotation results), and hypergeometric distribution test was used to calculate the significance of differential unigene enrichment in each pathway entry. The calculated results will return a p value of enrichment significance, and a small $p$ value indicates that differential unigene is enriched in this pathway. As shown in the figure, Pathway items corresponding to the number of different unigenes greater than 2 were screened and sorted from large to small according to the -log10pvalue corresponding to each item. X-axis is Enrichment Score, and entries with bigger bubbles contain more unigene diversity. The bubble color changes from violet - blue - green - red, and the smaller the enrichment $\mathrm{p}$ value is, the more significant it is.

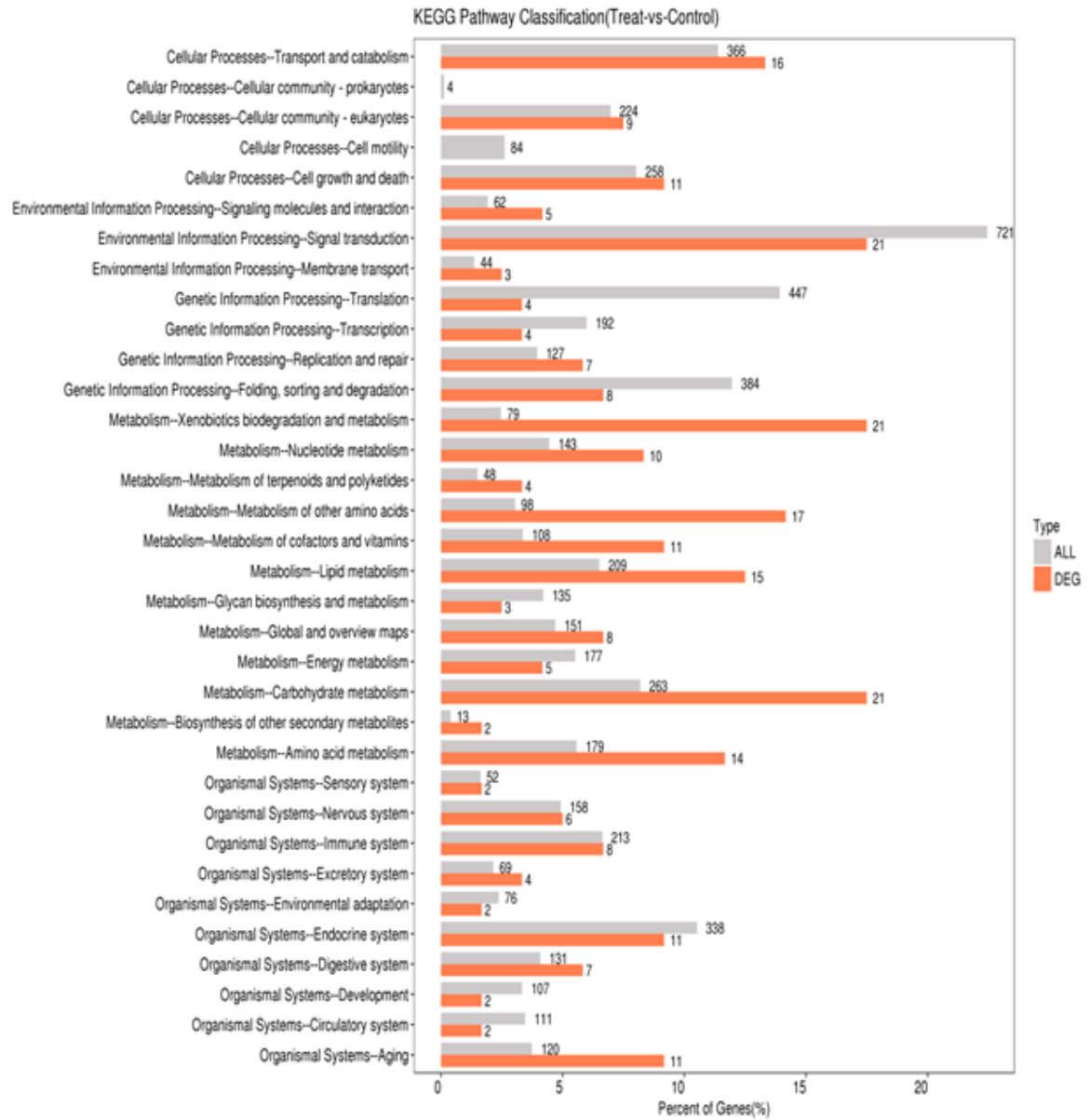

Figure 9 
Comparison chart of the distribution of differentially expressed unigenes and all unigenes at KEGG Level2. The X-axis is the ratio (\%) of the number of differentially expressed genes annotated to each Level2 metabolic pathway to all differentially expressed genes (orange), and the rate (\%) of all genes annotated to each Level2 metabolic pathway to the total number of genes (grey). The Y-axis is the name of the Level2 pathway; the number on the right of the column represents the number of differentially expressed unigene and all unigene annotated to this Level2 pathway.

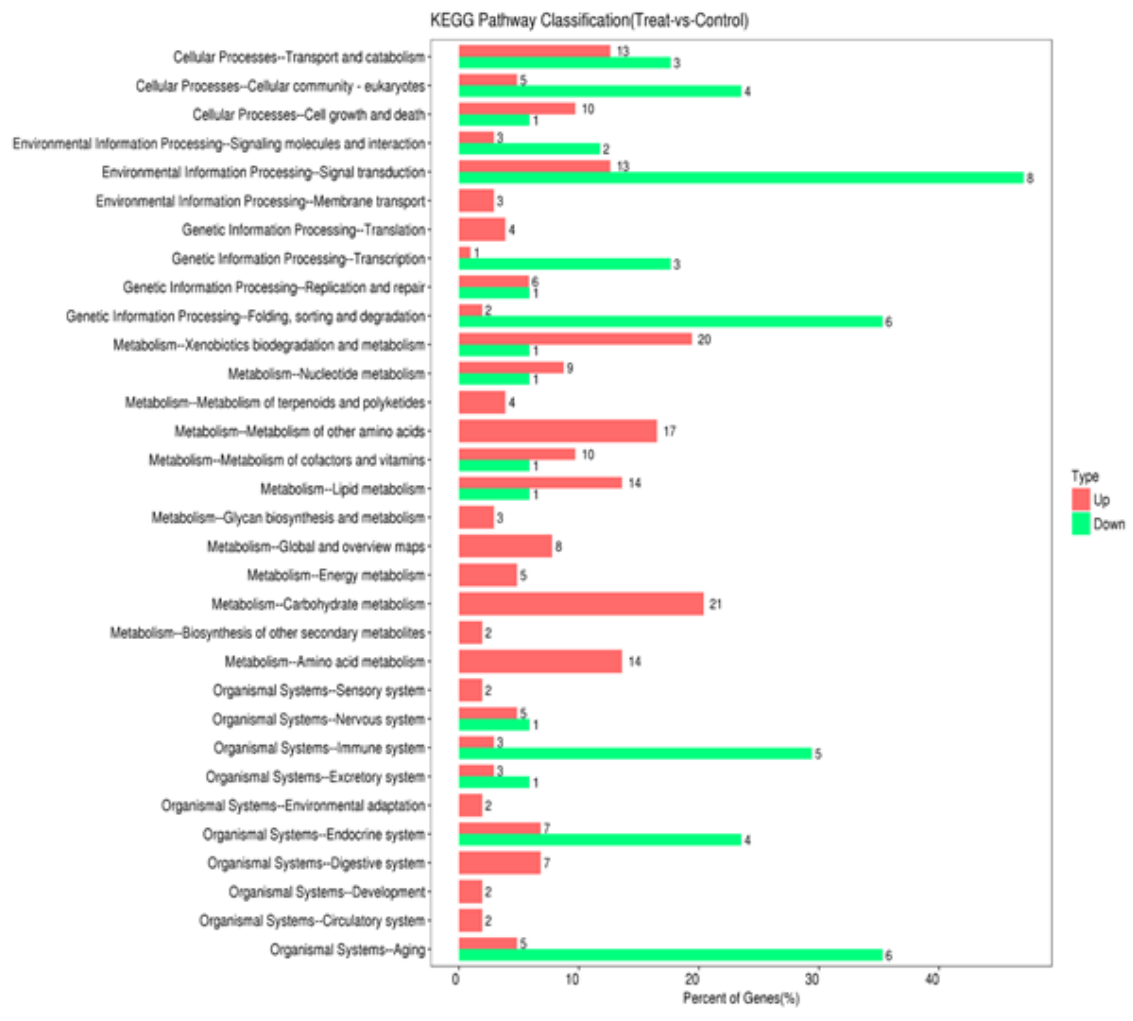

\section{Figure 10}

The distribution chart of upregulated and down-regulated differential expression of Unigene at KEGG Level2. The X-axis is the ratio (\%) of the number of upregulated unigene annotated to each Level2 metabolic pathway in the total number of upregulated unigene annotated to the KEGG pathway (red), and the ratio (\%) of the total number of down-regulated unigene annotated to each Level2 metabolic pathway in the total number of down-regulated unigene annotated to the KEGG pathway (green). The Y-axis represents the name of the Level2 pathway, and the number on the right of the column represents the number of upregulated (down-regulated) unigene annotated to this Level2 pathway.
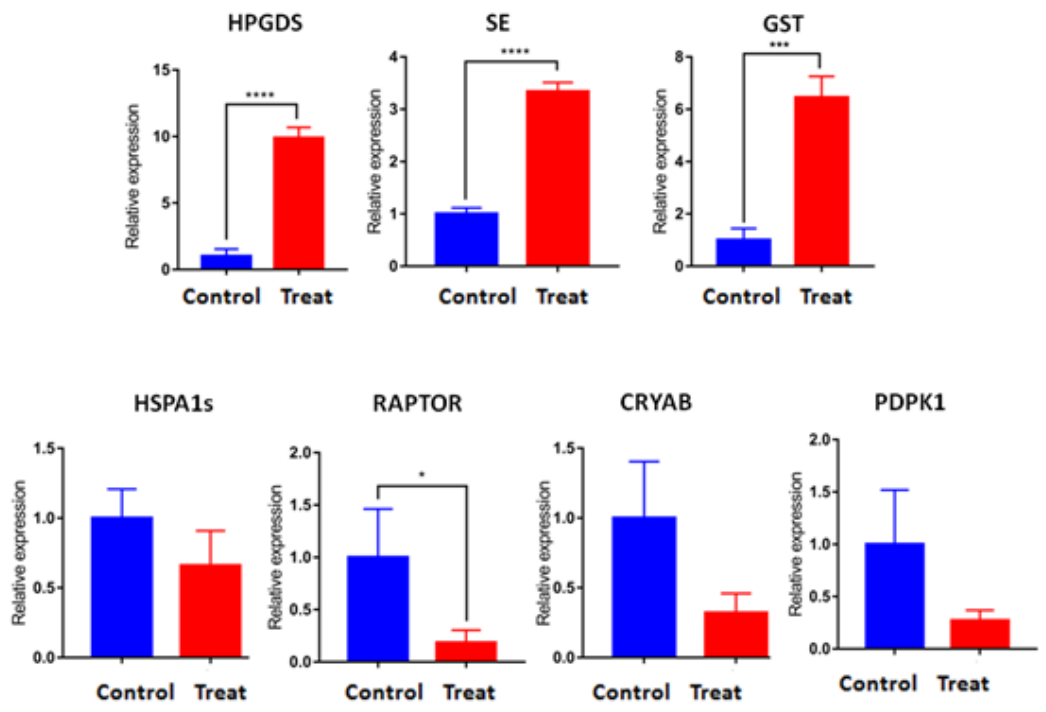

Figure 11 
Validation of differently expressed genes by qRT-PCR; qRT-PCR used the same RNA samples. All of the qRT-PCR data are shown as the mean \pm $S D ; n=3$. Their expression relative to 28 s was quantified by qRT-PCR. ${ }^{*} p<0.05,{ }^{* \star *} p<0.001,{ }^{* \star * *} p<0.0001$.

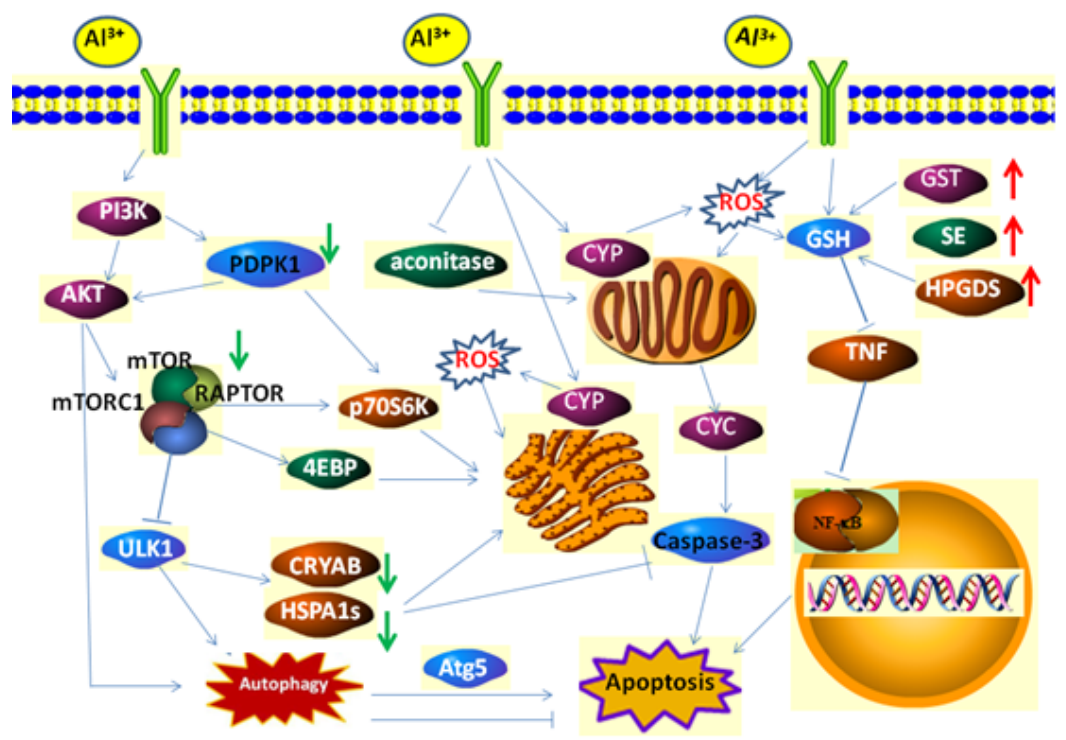

\section{Figure 12}

Diagram illustrates the possible mechanisms by which aluminum ions induce apoptosis and affect protein synthesis. The red arrows indicate upregulated genes, and the green arrows indicate down-regulated genes. 1. Aluminium ions reduce the expression of PKPK1 through PI3K-Akt pathway, further inhibit the expression of Raptor, and then affect the protein synthesis in the endoplasmic reticulum through p70S6K and 4EBP, and promote apoptosis through ULK1, HSPS and other proteins. 2. Aluminium ions affect GSH-related pathways to promote apoptosis by upregulating the expression of GST, HPGDS and SE proteins and producing ROS. 3. Aluminium may induce the uncoupling of CYP and catalyze the cyclic production of ROS, leading to multiple toxic effects on mitochondria and the endoplasmic reticulum. In turn, it affects endoplasmic reticulum protein synthesis and activates Caspase-3 and promotes apoptosis through the release of mitochondrial CYC.

\section{Supplementary Files}

This is a list of supplementary files associated with this preprint. Click to download.

- Supptables.docx 